\title{
Lung involvement in primary Sjögren's syndrome is mainly related to the small airway disease
}

Spyros A Papiris, Maria Maniati, Stavros H Constantopoulos, Charis Roussos, Haralampos M Moutsopoulos, Fotini N Skopouli

Department of Pulmonary and Critical Care Medicine, Eugenidio Hospital, Athens, Greece

S A Papiris

Department of Internal Medicine, Medical School, University of Ioannina, Ioannina, Greece M Maniati

S H Constantopoulos

Department of Critical Care Medicine, Medical School, National and Kapodestrian University, Athens, Greece

C Roussos

Department of Pathophysiology, Medical School, National and Kapodestrian University, Athens, Greece

H M Moutsopoulos

Department of Nutrition and Diatetics, Harokopio University, Athens, Greece

F N Skopouli

Correspondence to: Dr F N Skopouli, Department of Nutrition and Diatetics, Harokopio University, 70 El Venizelou Street, 17671 Athens, Greece.

Accepted for publication 23 September 1998
Abstract

Objective-To evaluate lung involvement in patients with primary Sjögren's syndrome.

Methods-Sixty one consecutive, nonsmoking patients, 58 women and three men, were evaluated clinically, physiologically, and radiologically. A bronchial and/or transbronchial biopsy was performed on 13 of the patients. Physiological data were compared with that of a control group of 53 healthy non-smoking subjects matched for age and sex.

Results-In $41 \%$ of the patients the main symptom was dry cough. Physiological studies revealed that the patients presented significantly lower expiratory flow values (\% pred) when compared with those of the control group: the forced expiratory volume in one second $\left(\mathrm{FEV}_{1}\right)$ (mean (SD)) was 96\% (16) v 111\% (13) $(\mathbf{p}<0.0001)$, the maximal expiratory flow at the $50 \%$ of the vital capacity $\left(\mathrm{MEF}_{50}\right)$ was $72 \%(24) v 103 \%(17)(p<0.0001)$, and the maximal expiratory flow at the $25 \%$ of the vital capacity $\left(\mathrm{MEF}_{25}\right)$ was $49 \%$ (25) $v$ $98 \%(20) \quad(p<0.0001)$. No significant difference was noted for the carbon monoxide diffusion value ( $\%$ pred), between patients and controls. Blood gases were evaluated in 44 patients: mild hypoxemia was observed, and the alveolo-arterial oxygen difference $\left(\mathrm{P}(\mathrm{A}-\mathrm{a}) \mathrm{O}_{2}\right)$ correlated significantly with $\mathrm{MEF}_{50}(r=0.35, \mathrm{p}<0.01)$ and $\mathrm{MEF}_{25}(r=0.33, \mathbf{p}<\mathbf{0 . 0 1})$ values. Chest radiography showed mild, interstitial-like changes in 27 patients while slightly increased markings were present in 21 . High resolution computed tomography of the lungs was performed in 32 patients (four with a normal chest radiograph, six with suspected interstitial pattern, 19 with apparent interstitial pattern, and three with hyperinflation) and revealed predominantly wall thickening at the segmental bronchi. All positive findings by computed tomography derived from the patients with abnormal chest radiographs. Transbronchial and/or endobronchial biopsy specimens in 10 of the 11 sufficient tissue samples revealed peri- bronchial and/or peribronchiolar mononuclear inflammation, while interstitial inflammation coexisted in two patients. Conclusion-The airway epithelia seem to be the main target of the inflammatory lesion of the lung in patients with primary Sjögren's syndrome. It seems to be common, subclinically leading to obstructive small airway physiological abnormalities. (Ann Rheum Dis 1999;58:61-64)

Sjögren's syndrome is a slowly progressive inflammatory autoimmune disease, characterised by lymphocyte mediated destruction of exocrine glands. ${ }^{1}$ Pulmonary involvement in "primary" Sjögren's syndrome, has been the subject of various studies. ${ }^{2-6}$ However, some discrepancy in the available literature exists concerning the frequency, the pattern of physiological abnormalities, and the clinical significance of the respiratory involvement in primary Sjögren's syndrome. Indeed the reported frequency of physiological abnormalities varies widely from 19 to $65 \%$, depending on the sensitivity of the selected physiological parameters and the criteria used to define abnormality. Moreover, there is some difficulty in obtaining a clear picture of the pattern of the physiological abnormalities described; some authors have reported a restrictive ${ }^{5}$ or mixed ventilatory ${ }^{6}$ defect while others report a relatively high incidence of small airways obstruction. ${ }^{4}$ Conflicting results arose also from prospective longitudinal follow up studies, which attempted to determine the true clinical significance of these abnormalities. Kelly and coworkers reported that respiratory involvement is an early feature of the syndrome and may progress over a relatively short period, ${ }^{6}$ while our previous studies showed that pulmonary involvement in primary Sjögren's syndrome is usually mild and very slowly progressive. ${ }^{7}$

In view of the pleomorphy of clinical expression reported and the diversity of physiological changes detected we performed clinical, physiological, radiological, and histopathological studies in a group of 61 patients with primary Sjögren's syndrome. 
Table 1 Pulmonary physiological data in primary Sjögren's syndrome (pSS) patients and normal controls

\begin{tabular}{|c|c|c|c|c|}
\hline \multirow[b]{2}{*}{ Physiological parameters } & \multicolumn{2}{|l|}{ pSS Patients } & \multicolumn{2}{|l|}{ Controls } \\
\hline & Mean (SD) & (range) & Mean (SD) & (range) \\
\hline $\mathrm{FEV}_{1} \dagger$ & $96 \quad(16)$ & $(56-129)^{\star}$ & $111(13)$ & $(85-137)$ \\
\hline $\mathrm{MEF}_{50} \dagger$ & $71.8(24.5)$ & $(22-128)^{\star}$ & $103(17)$ & $(71-141)$ \\
\hline $\mathrm{MEF}_{25} \dagger$ & $49.5(17.7)$ & $(18-125)^{\star}$ & $98(19.7)$ & $(61-148)$ \\
\hline DLCO & $85 \quad(17.7)$ & $(44-131) \mathrm{NS}$ & $95(21.3)$ & $(74-161)$ \\
\hline $\mathrm{PaO}_{2} \mathrm{~mm} \mathrm{Hg}$ & $84 \quad(13)$ & $(48-115)$ & & \\
\hline $\mathrm{kPa}$ & $11.9(1.7)$ & $(6.4-15.3)$ & & \\
\hline $\mathrm{P}(\mathrm{A}-\mathrm{a}) \mathrm{O}_{2} \mathrm{~mm} \mathrm{Hg}$ & $23.6(11.4)$ & $(1-49)$ & & \\
\hline $\mathrm{kPa}$ & $3.1(1.5)$ & $(0.1-6.5)$ & & \\
\hline
\end{tabular}

\section{Methods}

Sixty one consecutive and non-smoking patients with primary Sjögren's syndrome, diagnosed and followed up at the Department of Internal Medicine of the University of Ioannina, were evaluated for respiratory involvement. The diagnosis of primary Sjögren's syndrome was based on the European criteria. ${ }^{8}$

A detailed pulmonary history was obtained and physical examination was performed in every patient. Physiological evaluation (Transfer screen II/O, Erich Jeager, West Germany) included: flow volume curves and registration of the forced expiratory volume in one second $\left(\mathrm{FEV}_{1}\right)$, the forced vital capacity (FVC), the maximal expiratory flow at $50 \%$ of the vital capacity $\left(\mathrm{MEF}_{50}\right)$, and the maximal expiratory flow at $25 \%$ of the vital capacity $\left(\mathrm{MEF}_{25}\right)$. Maximal expiratory flows at 50 and $25 \%$ of the forced vital capacity are effort independent measurements of the end of expiration and are considered to reflect the status of the small peripheral airways of the lung. Carbon monoxide diffusion was measured using the single breath method (sbDLCO). ${ }^{9}$ The results of the pulmonary function tests were expressed as percentage of predicted values (Knudson et al, for spirometry and flow volume values, ${ }^{10}$ and Cotes, for the sbDLCO $^{9}$ ). Blood gases were obtained in 44 patients and the $\mathrm{P}(\mathrm{A}-\mathrm{a}) \mathrm{O}_{2}$ was calculated using the alveolar air equation, the simplified version of which is $\mathrm{PaO}_{2}=150-1.2 \times$ $\mathrm{PaCO}_{2}$, assuming a normal value for respiratory exchange ratio (0.8) and breathing $21 \%$ oxygen at sea level. $\mathrm{P}(\mathrm{A}-\mathrm{a}) \mathrm{O}_{2}$ was considered abnormal when it exceeded $10-15 \mathrm{~mm} \mathrm{Hg}$. Patients' physiological data were compared with that of a control group of 53 healthy, nonsmoking people, age and sex matched, selected from the hospital personnel and patients' relatives. None of the patients and control group had a history of lung disease.

Chest radiography in standard posteroanterior and lateral position was performed in all patients. Thirty two patients, were examined by computed tomography (CT) of the lung on a DR26 Somaton scanner, Siemens, Erlagen, Germany. Routine examination consisted of sequential $8 \mathrm{~mm}$ thick sections obtained at $1 \mathrm{~cm}$ intervals from the lung apex to the diaphragm (3 seconds 230 milliAmperes (mAs) 125 kilovolts (Kvp)). High resolution CT was additionally performed using a Siemens high spatial frequency algorithm and the following parameters $4 \mathrm{sec}, 310 \mathrm{mAs}, 125 \mathrm{kVp}$.
Bronchoscopy was performed, after informed written consent, in 13 patients. The study conformed to the declaration of Helsinki, and for ethical reasons transbronchial biopsy was suggested only in those patients with abnormal chest radiographs. The specimens after routine processing were stained with haematoxylin and eosin and evaluated on light microscope.

Descriptive analysis of different parameters was done using percentages and means. Student's $t$ test was used for comparison. Correlation of different parameters was performed using simple linear regression analysis.

\section{Results}

Fifty eight of the patients were female and three male with a mean (SD) age of 50 (11) years (range from 25 to 69) and mean (SD) disease duration 8 (4.7) years (range from 1 to 22). Twenty nine patients $(47.5 \%)$ had parotid gland enlargement and 23 (38\%) Raynaud's phenomenon. Serum evaluation for anti-Ro (SSA) autoantibodies was positive in 32 patients $(50 \%)$ and for anti-La (SSB) in 13 of them (21\%). Forty seven patients ( $85.4 \%$ ) had a lip biopsy $>2$ according to Chisolm criteria and the remaining were $=1$. Twenty four patients $(41 \%)$ complained of "sicca cough" and four (7\%) of mild breathlessness on exertion. On chest auscultation few end inspiratory rales were audible in eight patients (14\%).

Table 1 shows the pulmonary function data. All expiratory flow indices $\mathrm{FEV}_{1}, \mathrm{MEF}_{50}$, and $\mathrm{MEF}_{25}$ were lower than predicted in $72 \%, 87 \%$, and $97 \%$ of patients respectively. Mean (SD) values, expressed as per cent of predicted, were for $\mathrm{FEV}_{1} 96 \%$ (16) (range 56-129), for $\mathrm{MEF}_{50}$ $72 \%$ (24) (range 22-128), and for $\mathrm{MEF}_{25} 49 \%$ (25) (range 18-125). Seven patients (11\%) presented $\mathrm{FEV}_{1}$ values lower than $80 \%$ of predicted, while $30(50 \%)$ and $47(77 \%)$ presented $\mathrm{MEF}_{50}$ and $\mathrm{MEF}_{25}$ lower than $75 \%$ of predicted respectively. None of the people in the control groups presented $\mathrm{FEV}_{1}$ lower than $80 \%$ of predicted and two (4\%) and four (8\%) presented $\mathrm{MEF}_{50}$ and $\mathrm{MEF}_{25}$ lower than $75 \%$ of predicted respectively. The above parameters were significantly lower from those observed in the control group $(p<0.0001)$. None of the patients responded (improvement of $\mathrm{FEV}_{1}$ $\geqslant 15 \%$ ) to inhalation of $200 \mu \mathrm{g}$ salbutomol. In 55 patients a sbDLCO was obtained and was lower than $75 \%$ of predicted in 12 patients $(22 \%)$. The mean value for sbDLCO in patients was 85 (18) $v 95$ (21) in the control group ( $\mathrm{p}=0.076)$. The mean $\mathrm{PaO}_{2}$ was 84 (13) $\mathrm{mm} \mathrm{Hg}(\mathrm{kPa} 11.9$ (1.7)) with range 48-115 $\mathrm{mm} \mathrm{Hg}\left(\mathrm{kPa}\right.$ 6.4-15.3). Ten patients had $\mathrm{PaO}_{2}$ $<80 \mathrm{~mm} \mathrm{Hg}$. $\mathrm{P}(\mathrm{A}-\mathrm{a}) \mathrm{O}_{2}$ ranged between 1-49 $\mathrm{mm} \mathrm{Hg}(0.13-6.53 \mathrm{kPa})$ with a mean (SD) value of $23.6(11.4)(3.14(1.51) \mathrm{kPa})$. Using simple linear regression analysis $\mathrm{P}(\mathrm{A}-\mathrm{a}) \mathrm{O}_{2}$ correlated positively with $\mathrm{MEF}_{50}(r=0.35, \mathrm{p}<0.01)$ and $\mathrm{MEF}_{25} \quad(r=0.39, \mathrm{p}<0.01)$ but not with $\operatorname{sbDLCO}(r=0.03, \mathrm{p}<0.85)$. No significant correlation was found between patient's age, symptoms, disease duration, degree of lymphocytic infiltration on salivary gland biopsies, 


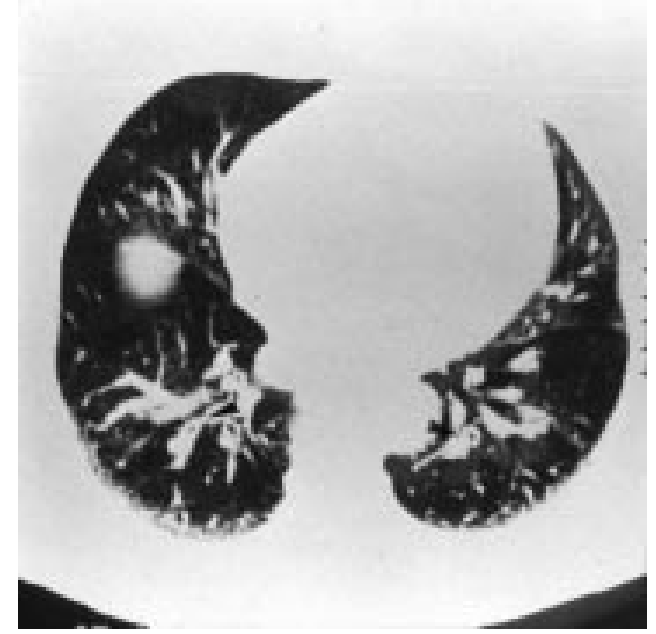

Figure 1 High resolution CT of the lung in a patient with primary Sjögren's syndrome: thickened bronchial walls at segmental level are evident (arrows).

presence of autoantibodies to $\operatorname{Ro}(\mathrm{SSA})$ and $\mathrm{La}(\mathrm{SSB})$, and physiological parameters.

On chest radiography a mild interstitial pattern was present in 27 patients (44\%) while slightly increased markings were noted in 21 $(34 \%)$. Evidence of hyperinflation was observed in three patients. High resolution CT of the lung was performed in 32 patients (four with a normal chest radiograph, six with increased markings, 19 with apparent interstitial pattern, and three hyperinflation on radiographs). Abnormalities were seen only in 10 patients. These included: thickened walls of the segmental bronchi in seven patients (fig 1) and multiple bullae in three other patients. Other coexisting findings in the patients with thickened wall were: cylindrical bronchiectasis in the lower lobes in two patients, interstitial pattern (ground glass or small nodular pattern) in two other patients, centrilobular branching structures within the secondary lobule with ground glass appearance in two other patients. The remaining high resolution CT lung scans were normal. All positive findings derived from the patients with abnormal chest radiographs.

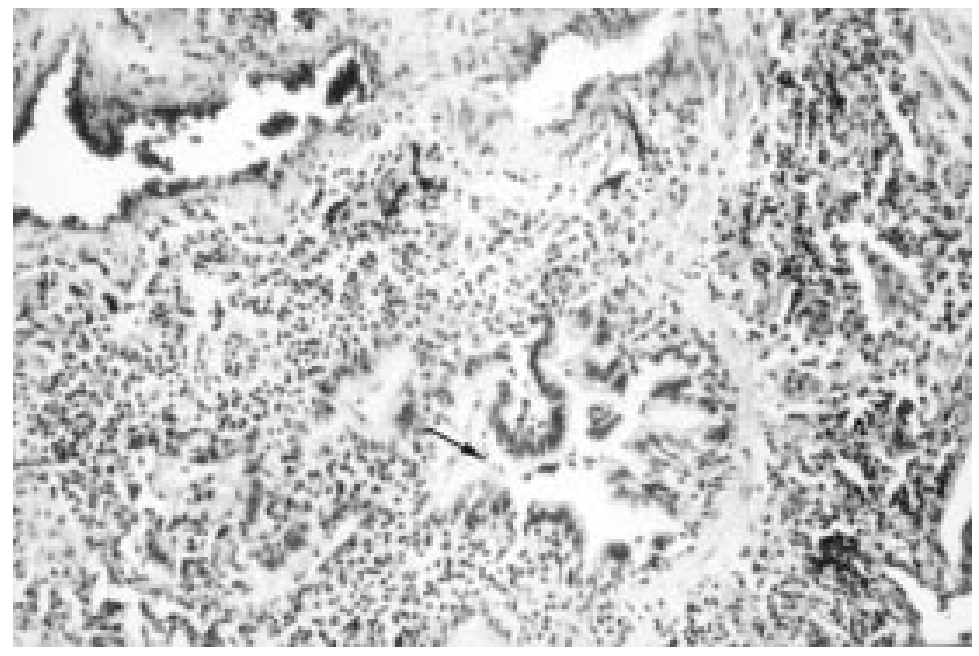

Figure 2 Mononuclear infiltrates around small bronchioli (arrow points to airway lumen) (haematoxylin and eosin staining, original magnification $\times 200$ ).
The transbronchial biopsy specimens included bronchiolar and alveolar tissue in 11 patients while in two the tissue specimen was not sufficient. In six of these patients additional endobronchial biopsies were performed. Submucosal mononuclear infiltrates were observed in both large and small bronchi in 10 patients (fig 2), follicular bronchiolitis was observed in two of them, and interstitial pneumonitis in another two.

All the patients with abnormal lung histopathology had an interstitial-like pattern on chest radiography. Seven had thickening of the segmental bronchial walls on high resolution CT. All patients had physiological indices compatible with small airway obstruction and five had $\mathrm{PO}_{2}<80^{\circ} \mathrm{mm} \mathrm{Hg}$. Seven patients complained of cough while only three had inspiratory rales on auscultation.

\section{Discussion}

This study shows that lung involvement in patients with primary Sjögren's syndrome is common and mostly subclinical. Physiological, radiological, and histological findings suggest that the lesions affect the bronchial tree and particularly the small bronchioles.

The main histological lesion in primary Sjögren's syndrome consists of focal lymphocytic infiltrates of the exocrine glands. These lymphocytic infiltrates start usually around salivary and lacrymal ducts and extend slowly and gradually, replacing the physiological glandular epithelium, thus producing dry mouth and eyes. ${ }^{11}$ Similar lesions have been seen in extraglandular organs like the kidney and the liver. In the kidney, peritubular lymphocytic infiltrates induce tubular dysfunction while in the liver, periductul infiltrates lead to a clinicoserological picture of primary biliary cirrhosis. ${ }^{11}$

This study clearly shows that the lesion in the lung of patients with primary Sjögren's syndrome consists of peribronchial lymphocytic infiltrates. This lesion does not differ from that described in the exocrine glands and other parenchyma organs of these patients. All these clinical findings suggest that the major cell target for “autoimmunity” in primary Sjögren's syndrome is the epithelium. ${ }^{11}$

The lung lesion does not seem to produce a severe clinical syndrome. Most patients suffer only from dry cough without specific clinical findings. Dry cough has been described by Constantopoulos et $a l^{\beta}$ as being the main respiratory symptom of primary Sjögren's syndrome patients and has been named "xerotrachea" following the equivalence of xerostomia and xerophthalmia. Dry cough has been described also by Sjögren himself 65 years ago, later named "bronchitis sicca" by Alarcon-Segovia. ${ }^{12}$ The cough is probably caused by desiccation of the mucosa of the tracheobronchial tree. However, it had never been associated with physiological and histological findings. ${ }^{13}$

In our study physiological tests showed that most patients presented low $\mathrm{MEF}_{50}$ and $\mathrm{MEF}_{25}$. The maximal mid-expiratory flow rate is often considered a more sensitive measurement of early airflow obstruction, particularly in small airways. However, these measurements 
must be interpreted cautiously because the tests are less reproducible. On the other hand in primary Sjögren's syndrome patients sequencial tests during routine follow up gave similar results (data not shown). It is of interest to note also that the low arterial $\mathrm{PO}_{2}$ observed in some patients seems to be the result of small airway obstruction as the patient's DLCO was almost normal and the $\mathrm{P}(\mathrm{A}-\mathrm{a}) \mathrm{O}_{2}$ correlated positively only with decreased $\mathrm{MEF}_{50}$ and $\mathrm{MEF}_{25}$. However, clinically relevant airway obstruction was observed only in six patients $(10 \%)$. Small airway obstruction has also been confirmed by other investigators. ${ }^{41-16}$ Newball and Brahim $^{14}$ described 6 of 13 primary Sjogren's syndrome patients to have bronchial obstruction and mononuclear cell infiltration of the small airways. Mononuclear cells infiltrating the small airway wall leading to anatomical obstruction could explain the physiological abnormalities observed in primary Sjögren's syndrome patients. Cytokines produced locally by these cells could also contribute to this physiological disturbance. More detail studies are necessary to clarify this issue.

Furthermore, it should be pointed out that although chest radiographic findings of primary Sjogren's syndrome patients are reminiscent of an interstitial disorder this actually corresponds to thickened bronchioles. Using high resolution CT of the lung we detected thickened bronchial walls at the basilar segmental bronchi in seven patients. This finding probably reflects the degree of mononuclear infiltrates observed in endobronchial biopsy. Interstitial involvement was evident in only 4 of 21 patients examined by high resolution CT. It consisted of ground glass appearance or fine nodular pattern distributed predominantly peribronchially. Peripheral and lower lobe distribution typical of fibrosing alveolitis ${ }^{17}$ as well as honey combing ${ }^{18}$ were absent in all patients.

From this study there is growing evidence of a close relation between the abnormal physiology of the bronchial tree and the pathogenesis of respiratory manifestations of Sjögren's syndrome. The proposed hypothesis is that all lung lesions of primary Sjögren's syndrome originate from the airways. At the initial stages lymphocytic infiltrates are localised to exocrine submucosal glands in both large and small airways at a subepithelial level. ${ }^{19}$ As the disease progresses follicular bronchiolitis ${ }^{20}$ becomes evident while the dysfunction of the large airway exocrine glands leads to xerotrachea and xerobronchitis. In a minority of patients, spreading of immunocytes towards the alveolar structures occurs. This, however, does not evolve to interstitial fibrosing alveolitis. Our clinical, physiological, radiological, and histological findings seem to support this sequence of events.

We thank Dr Galifallia Linardaki and Mrs Pola Papadopoulou for editorial and secretarial assistance.

1 Moutsopoulos HM, Chused TM, Mann DL, Klippel JH, Fauci AS, Frank MM, et al. Sjögren's syndrome (sicca synFauci AS, Frank MM, et al. Sjögren's syndrome (sicca syn-
drome): current issues. Ann Intern Med 1980;92 drome): current

2 Linstow M, Kriegbaum NJ, Backer V, Ulrik C, Oxholm PA. Follow-up study of pulmonary function in patients with primary Sjögren's syndrome. Rheumatol Int 1990;10: $47-9$.

3 Constantopoulos SH, Drosos AA, Maddison PJ, Moutsopoulos HM. Xerotrachea and interstitial lung disease in primary Sjögren's syndrome. Respiration 1984;46:310-14.

4 Constantopoulos SH, Papadimitriou CS, Moutsopoulos HM. Respiratory manifestations in primary Sjögren's syndrome. A clinical functional and histological study. Chest 1985;88:226-9.

5 Gardiner P, Ward C, Allison A, Ashcroft T, Simpson W, Walters H, et al. Pleuropulmonary abnormalities in primary Sjögren's syndrome. J Rheumatol 1993;20:831-7.

Kelly C, Gardiner P, Pal B, Griffiths I. Lung function in primary Sjögren's syndrome: a cross

7 Constantopoulos SH, Moutsopoulos HM. Respiratory involvement in patients with primary Sjögren's syndrome. Is it a problem? Scand J Rheumatol 1986;61(suppl):14650 .

8 Vitali C, Bombardieri S, Moutsopoulos HM, Balestreri G, Bencivelli W, Bernstein RM, et al. Preliminary criteria for the classification of Sjögren's syndrome: results of a prospective concerted action supported by the European Community. Arthritis Rheum 1993;36:340-7.

9 Cotes LE. Lung function: assessment and application in medicine. 3rd ed. London: Blackwell Scientific Publications, 1975.

10 Knudson RJ, Statin RC, Lebovitz MD, Burrows B. The maximal expiratory flow-volume curve: normal standards, variability and effects of age. Am Rev Respir Dis 1976;113: 587-600.

11 Moutsopoulos HM. Sjögren's syndrome: autoimmune epithelitis. Clin Immunol Immunopathol 1994;72:162-5.

12 Alarcon Segovia D. Airways in rheumatoid disease. [Letter]. Lancet 1978;ii: 1058 .

13 Bariffi F, Pesci A, Bertorelli G, Manganelli P, Ambanelli V. Pulmonary involvement in primary Sjögren's syndrome. Respiration 1984;46:82-6.

14 Newball HH, Brahim SA. Chronic obstructive airway disease in patients with Sjögren's syndrome. Am Rev Respir Dis 1977;115:295-304.

15 Segal I, Fink G, Machtey I, Gura V, Spitzer SA. Pulmonary function abnormalities in Sjögren's syndrome and the sicca complex. Thorax 1981;36:286-9.

16 Lahdensuo A, Korpela M. Pulmonary findings in patients with primary Sjögren's syndrome. Chest 1995;108:31619.

17 Cairns D, Shelley L, Burke WMJ, Bryant DH, Yeates M, Penny $R$, et al. The differings pattern of interstitial lung involvement in connective tissue diseases. J Rheumatol 1992;19:1089-95.

18 Muller NL, Miller RR. Computed tomography of chronic diffuse infiltrative lung disease. State of the Art. Part 1 and diffuse infiltrative lung disease. State of the Art. Part
2. Am Rev Respir Dis 1990;142:1206-15, 1440-8.

19 Papiris SA, Saetta M, Turato G, LaCorte R, Trevisani L, Papp CE, et al. CD4 positive T-lymphocytes infliltrate the bornchial mucosa of patients with Sjögren's syndrome. Am J Respir Crit Care Med 1997;156:637-41

20 Yousem SA, Colby TV, Carrington CB. Follicular bronchitis/bronchiolotis. Hum Pathol 1985;16:700-6. 